\title{
Details about informed consent procedures of randomized controlled trials should be reported transparently
}

Citation for published version (APA):

Kotz, D., Viechtbauer, W., Spigt, M., \& Crutzen, R. (2019). Details about informed consent procedures of randomized controlled trials should be reported transparently. Journal of Clinical Epidemiology, 109, 133135. https://doi.org/10.1016/j.jclinepi.2019.01.007

Document status and date:

Published: 01/05/2019

DOI:

10.1016/j.jclinepi.2019.01.007

Document Version:

Publisher's PDF, also known as Version of record

Document license:

Taverne

Please check the document version of this publication:

- A submitted manuscript is the version of the article upon submission and before peer-review. There can be important differences between the submitted version and the official published version of record.

People interested in the research are advised to contact the author for the final version of the publication, or visit the DOI to the publisher's website.

- The final author version and the galley proof are versions of the publication after peer review.

- The final published version features the final layout of the paper including the volume, issue and page numbers.

Link to publication

\footnotetext{
General rights rights.

- You may freely distribute the URL identifying the publication in the public portal. please follow below link for the End User Agreement:

www.umlib.nl/taverne-license

Take down policy

If you believe that this document breaches copyright please contact us at:

repository@maastrichtuniversity.nl

providing details and we will investigate your claim.
}

Copyright and moral rights for the publications made accessible in the public portal are retained by the authors and/or other copyright owners and it is a condition of accessing publications that users recognise and abide by the legal requirements associated with these

- Users may download and print one copy of any publication from the public portal for the purpose of private study or research.

- You may not further distribute the material or use it for any profit-making activity or commercial gain

If the publication is distributed under the terms of Article 25fa of the Dutch Copyright Act, indicated by the "Taverne" license above, 


\title{
COMMENTARY
}

\section{Details about informed consent procedures of randomized controlled trials should be reported transparently}

\author{
Daniel Kotz ${ }^{\mathrm{a}, \mathrm{b}, *}$, Wolfgang Viechtbauer ${ }^{\mathrm{c}}$, Mark Spigt ${ }^{\mathrm{b}}$, Rik Crutzen ${ }^{\mathrm{d}}$ \\ ${ }^{a}$ Institute of General Practice, Addiction Research and Clinical Epidemiology Unit, Medical Faculty of the Heinrich-Heine-University, Düsseldorf, Germany \\ ${ }^{\mathrm{b}}$ Department of Family Medicine, CAPHRI School for Public Health and Primary Care, Maastricht University, The Netherlands \\ ${ }^{\mathrm{c}}$ Department of Psychiatry and Neuropsychology, School for Mental Health and Neuroscience, Maastricht University \\ ${ }^{\mathrm{d}}$ Department of Health Promotion, CAPHRI School for Public Health and Primary Care, Maastricht University, The Netherlands
}

Accepted 21 January 2019; Published online 30 January 2019

\section{Commentary}

Informing potential participants about the aims and procedures of a trial is mandatory when seeking their consent. A description of the potential benefits and harms of the intervention and control conditions is an integral part of the information that should be provided. The World Medical Association's Declaration of Helsinki from 1964 [1] is the most often used guideline when it comes to the content of informed consent. It states that "the nature, the purpose and the risk of clinical research must be explained to the subject by the doctor.' In addition, the Declaration of Helsinki explicitly states that consent should, as a rule, be obtained in writing. Research ethics committees are used to check whether the informed consent procedures proposed by researchers adhere to this general guideline. Current practice in obtaining informed consent seems to have been shaped by emphasis on the legal duty of disclosure; consent is seen as an action, concluded by signing a form [2]. In line with this administrative attitude toward informed consent, the procedure is standardly reported in a research article.

However, the exact information that is given to potential participants is often not understood by them $[3,4]$. At the same time, this information affects their decision to accept or refuse the invitation to take part in a trial [5-7], for example, because of the description of the expected treatment effect [8] or the extent to which pain is emphasized in the provided information [9]. Furthermore, the information may also affect the behavior of participants during the

Funding: The authors have not received any funding for the current report.

Conflict of interest: The authors declare to have no conflict of interest.

* Corresponding author. Institute of General Practice, Addiction Research and Clinical Epidemiology Unit, Medical Faculty of the Heinrich-Heine-University Düsseldorf, P.O. Box 101007, 40001 Düsseldorf, Germany. Tel.: +49-211-81-16327, fax: +49-211-81-08622. E-mail address: Twitter:@daniel_kotz (D. Kotz). trial (in particular regarding trials where participants cannot be blinded), for example, dissatisfaction with not receiving a potentially beneficial treatment or loyalty to those providing the treatment [10], which might also lead to dropout [11]. It is therefore important to know, when interpreting findings from a trial, how participants were informed about their participation.

Guidelines such as Consolidated Standards of Reporting Trials (CONSORT) [12] have been developed to improve the reporting of trials. Implementation of such guidelines and endorsement by leading medical journal editorial organizations have led to better reporting of trials, although the current reporting is still not optimal [13-17]. Because the first version of CONSORT, which was published in 1996 [18], several updates and extensions have been published (www.consort-statement.org). Until to date, however, these guidelines do not include a statement with regard to the reporting of the informed consent procedure of trials. This may be a reason why details about informed consent procedures of randomized controlled trials are currently poorly reported as our research shows.

We used the data frame of a systematic review including a random sample of 100 medical trials [19] to assess which information on informed consent procedures is commonly reported. Whereas almost all reports (92/100) included a statement that informed consent was sought from participants, only very few (6/100) reports included some details about how exactly participants were informed. However, the given information was often very brief (see examples in Box 1). No report $(0 / 100)$ referred to a publication with additional detailed information or provided the original participant information as supplementary material (full data from this analysis can be found on the Open Science Framework: https://osf.io/fx3m7/).

We argue that details about informed consent procedures of randomized controlled trials should be reported transparently. We propose that essential features of the information for participants are very briefly summarized in the methods section of 


\section{Box 1 Examples of the reporting of details about the informed consent procedure in trial publications}

"Each patient signed a consent form before being included in the study, and all patients were informed about both arms of the trial (CPAP and sham CPAP as placebo-CPAP at a very low pressure $(<1 \mathrm{~cm} \mathrm{H20})$ without any known therapeutic effect)." [20].

"All eligible mothers were informed by the fieldworkers about the overall aims of the study (advice on feeding of infants and its effects on the child's health) as well as all research procedures, including use of a questionnaire, anthropometric and blood hemoglobin measurement, dental examination, and differences between the intervention and control groups." [21].

"To ensure equipoise, the description of the study to patients and their physicians emphasized the possible benefits and limitations of both the intervention and usual care conditions." [22].

a trial report and that the full, original participant information letter (and ideally also an English translation if necessary) is published alongside the report as supplementary material or using platforms such as the Open Science Framework. This fits with the current move toward a more open research culture in which transparency, openness, and reproducibility are vital features [23-26]. We further recommend including a respective statement in a future version of CONSORT and related guidelines on the reporting of detailed information about the informed consent procedure, in particular how potential benefits and harms of the intervention and control conditions were communicated to participants.

\section{Acknowledgments}

The authors thank Yekaterina Pashutina and Esther Scholz for the help with extracting data from the 100 trial reports.

\section{References}

[1] World Medical Association. WMA Declaration of Helsinki - Ethical Principles for Medical Research Involving Human Subjects. Available at https://www.wma.net/what-we-do/medical-ethics/ declaration-of-helsinki/doh-jun1964/. Accessed November 23, 2018.

[2] Jefford M, Moore R. Improvement of informed consent and the quality of consent documents. Lancet Oncol 2008;9:485-93.

[3] Flory J, Emanuel E. Interventions to improve research participants' understanding in informed consent for research: a systematic review. JAMA 2004;292:1593-601.

[4] Nishimura A, Carey J, Erwin PJ, Tilburt JC, Murad MH, McCormick JB. Improving understanding in the research informed consent process: a systematic review of 54 interventions tested in randomized control trials. BMC Med Ethics 2013;14:28.
[5] Fanaroff Alexander C, Li S, Webb Laura E, Miller V, Navar AM, Peterson ED, et al. An observational study of the association of video- versus text-based informed consent with multicenter trial enrollment. Circ Cardiovasc Qual Outcomes 2018;11(4):e004675.

[6] Crutzen R, Bosma H, Havas J, Feron F. What can we learn from a failed trial: insight into non-participation in a chatbased intervention trial for adolescents with psychosocial problems. BMC Res Notes 2014;7:824.

[7] Treweek S, Pitkethly M, Cook J, Kjeldstrom M, Taskila T, Johansen M, et al. Strategies to improve recruitment to randomised controlled trials. Cochrane Database Syst Rev 2010; MR000013.

[8] Simelt DL, Feussner JR. A randomized controlled trial comparing quantitative informed consent formats. J Clin Epidemiol 1991;44: $771-7$.

[9] Treschan TA, Scheck T, Kober A, Fleischmann E, Birkenberg B, Petschnigg B, et al. The influence of protocol pain and risk on patients' willingness to consent for clinical studies: a randomized trial. Anesth Analg 2003;96(2):498-506.

[10] Dennis M. Commentary: why we didn't ask patients for their consent. BMJ 1997;314:1077.

[11] Schellings R, Kessels AG, ter Riet G, Sturmans F. The Zelen design may be the best choice for a heroin-provision experiment. J Clin Epidemiol 1999;52:503-7.

[12] Schulz KF, Altman DG, Moher D. CONSORT 2010 Statement: updated guidelines for reporting parallel group randomised trials. J Clin Epidemiol 2010;63:834-40.

[13] Bigna JJ, Noubiap JJ, Asangbeh SL, Um LN, Sime PS, Temfack E, et al. Abstracts reporting of HIV/AIDS randomized controlled trials in general medicine and infectious diseases journals: completeness to date and improvement in the quality since CONSORT extension for abstracts. BMC Med Res Methodol 2016;16:138.

[14] Hussain JA, Bland M, Langan D, Johnson MJ, Currow DC, White IR. Quality of missing data reporting and handling in palliative care trials demonstrates that further development of the CONSORT statement is required: a systematic review. J Clin Epidemiol 2017;88:81-91.

[15] Kuriyama A, Takahashi N, Nakayama T. Reporting of critical care trial abstracts: a comparison before and after the announcement of CONSORT guideline for abstracts. Trials 2017;18(1):32.

[16] Song SY, Kim B, Kim I, Kim S, Kwon M, Han C, et al. Assessing reporting quality of randomized controlled trial abstracts in psychiatry: adherence to CONSORT for abstracts: a systematic review. PLoS One 2017;12(11):e0187807.

[17] Turner L, Shamseer L, Altman DG, Weeks L, Peters J, Kober T, et al. Consolidated standards of reporting trials (CONSORT) and the completeness of reporting of randomised controlled trials (RCTs) published in medical journals. Cochrane Database Syst Rev 2012; 11:Mr000030.

[18] Begg C, Cho M, Eastwood S, Horton R, Moher D, Olkin I, et al. Improving the quality of reporting of randomized controlled trials. The CONSORT statement. JAMA 1996;276:637-9.

[19] Crutzen R, Viechtbauer W, Kotz D, Spigt M. No differential attrition in randomized controlled trials published in general medical journals: a meta-analysis. J Clin Epidemiol 2013;66:948-54.

[20] Duran-Cantolla J, Aizpuru F, Montserrat JM, Ballester E, TeranSantos J, Aguirregomoscorta JI, et al. Continuous positive airway pressure as treatment for systemic hypertension in people with obstructive sleep apnoea: randomised controlled trial. BMJ 2010; 341:c5991.

[21] Vitolo MR, Bortolini GA, Dal Bo Campagnolo P, Feldens CA. Effectiveness of a nutrition program in reducing symptoms of respiratory morbidity in children: a randomized field trial. Prev Med 2008;47: 384-8. 
[22] Davidson KW, Rieckmann N, Clemow L, Schwartz JE, Shimbo D, Medina V, et al. Enhanced depression care for patients with acute coronary syndrome and persistent depressive symptoms: coronary psychosocial evaluation studies randomized controlled trial. Arch Intern Med 2010;170:600-8.

[23] Kotz D, Tugwell P, Knottnerus JA. How to promote transparency and accountability in clinical and behavioral research. J Clin Epidemiol 2016;70:275.
[24] Nosek BA, Alter G, Banks GC, Borsboom D, Bowman SD, Breckler SJ, et al. SCIENTIFIC STANDARDS. Promoting an open research culture. Science 2015;348:1422-5.

[25] Peters GJ, Abraham C, Crutzen R. Full disclosure: doing behavioural science necessitates sharing. Eur Health Psychol 2012;14(4): 77-87.

[26] Crutzen R, Peters G-JY, Abraham C. What about trialists sharing other study materials? BMJ 2012;345:e8352. 